\title{
Influence of cartilage interstitial fluid on the mRNA levels of matrix proteins, cytokines, metalloproteases and their inhibitors in synovial membrane
}

\author{
ANNA HYC, STANISLAW MOSKALEWSKI and ANNA OSIECKA-IWAN \\ Department of Histology and Embryology, Medical University of Warsaw, PL-02004 Warsaw, Poland
}

Received February 18, 2016; Accepted June 16, 2016

DOI: $10.3892 /$ ijmm.2016.2684

\begin{abstract}
Articular cartilage and the synovial membrane both ensure the smooth action of synovial joints; however, the influence of chondrocytes on synovial metabolism remains unclear. The secretory activity of chondrocytes is usually studied in cell cultures and may differ from that in intact cartilage. According to McCutchen's theory of 'weeping' joint lubrication, loading of the articular cartilage during motion squeezes the fluid with lubricating properties from the cartilage. The purpose of the study was to obtain cartilage interstitial fluid (CIF) from intact cartilage and to evaluate its influence on gene expression in the synovial membrane cells. CIF was rinsed out from the cartilage of newborn rats at a pressure of three bar. The chondrocytes survived rinsing and grew in culture. Cytokines in CIF were detected using the enzyme-linked immunosorbent assay (ELISA). The influence of CIF and CIF-like cocktail (all cytokines found in CIF) on gene expression in the synovial membrane cells was studied after a $4 \mathrm{~h}$-incubation, by real-time PCR. Data were analyzed using the Wilcoxon matched-pair test or by the Mann-Whitney U test. CIF contained basic fibroblast growth factor (bFGF), insulin-like growth factor (IGF)-1, transforming growth factor $\beta 1$ (TGF $\beta 1$ ), bone morphogenetic protein 7 (BMP7), macrophage (M)-colony-stimulating factor (CSF), granulocyte (G)-CSF and leukemia inhibitory factor (LIF). CIF stimulated the expression of hyaluronan synthase (HAS) 1 and 2, lubricin, collagen I, versican, aggrecan, matrix metalloproteinases (MMPs)2 and 3, tissue inhibitors of metalloproteinases (TIMPs) 1-3, interleukin (IL)-6 and TGF $\beta 1$, and decreased the expression of tumor necrosis factor (TNF) and IL-1 $\beta$. Incubation of the synovial membrane with CIF-like

Correspondence to: Dr Anna Hyc or Dr Anna Osiecka-Iwan, Department of Histology and Embryology, Medical University of Warsaw, Chalubińskiego 5, PL-02004 Warsaw, Poland

E-mail: ahyc@wum.edu.pl

E-mail: aiwan@wum.edu.pl
\end{abstract}

Abbreviation: CIF, cartilage interstitial fluid

Key words: cartilage interstitial fluid, synovial membrane, chondrocyte, articular cartilage, synoviocyte cocktail partially imitated the effects of CIF. Analysis of CIF composition may help to characterize the secretory activity of chondrocytes in their natural environment under various physiological and pathological conditions and to understand the interactions between articular cartilage and the synovial membrane.

\section{Introduction}

Articular cartilage and the synovial membrane (SM) are the main components of synovial joints. The SM produces hyaluronic acid and lubricin, which are important for articular cartilage lubrication $(1,2)$. Synoviocytes also secrete factors which induce the synthesis of metalloproteinases by chondrocytes (3). Moreover, normal synovial fluid stimulates the synthesis of collagen type II and glycosaminoglycans in articular cartilage (4). The question remains, whether cartilage is a passive beneficiary of SM activity or whether chondrocytes can also influence the metabolism of cartilage by cytokines or other factors. Chondrocyte survival and differentiation require their interaction with extracellular matrix (5). The secretory activity of chondrocytes is usually studied in vitro, after their release from the matrix, but such an approach has some limitations. The yield of isolated cells is low in comparison with their content in cartilage, possibly resulting in the uncontrolled selection of certain chondrocyte subpopulations (6). Furthermore, the application of enzymes for the purpose of chondrocyte isolation changes their gene expression (7). Chondrocytes cultured as a monolayer downregulate the expression of cartilage matrix molecules such as collagen type II and aggrecan as well as increase the expression of collagen type I and versican, which is typical of fibroblast-like cells (8-10). They also undergo other changes in phenotype expression with the upregulation of markers regarded as distinctive for mesenchymal stem cells (11).

Cultured in vitro articular chondrocytes, particularly after stimulation by proinflammatory agents, secrete numerous cytokines, matrix metalloproteinases (MMPs), tissue inhibitors of metalloproteinases (TIMPs) and other factors (12). These experiments, however, were performed on cells released from the cartilage and thus, it is difficult to estimate the type of cytokine and the rate of production by chondrocytes in their natural environment, without modifications imposed by enzymatic baths or culture conditions. 
In this study, we aimed to establish which cytokines are produced by chondrocytes in the cartilage and also, to evaluate the influence of these cytokines on the SM as a possible target organ. The concept of the study emerged from the McCutchen (13) theory of 'weeping' lubrication in synovial joints. According to this study and others $(14,15)$ cartilage matrix contains a fluid phase, representing about $70 \%$ of its volume. During joint loading, about $10 \%$ of this liquid is squeezed from the cartilage surface (which, in a molecular sense, is porous) into the intraarticular cavity, and is responsible for hydrostatic lubrication. It is, therefore, plausible that cartilage interstitial fluid (CIF) squeezed from cartilage during joint loading contains cytokines produced by chondrocytes.

We have previously demonstrated that rat SM dissected from the knee joint and incubated in vitro responded to stimulation with cytokines and lipopolysaccharide by increasing the production of hyaluronic acid and changing the mRNA expression of hyaluronan synthases (HASs), cytokines, MMPs and TIMPs $(16,17)$. These findings suggested that the SM in this experimental model would also respond to factors present in the CIF. CIF was obtained by rinsing out the interstitial fluid from the dissected articular-epiphyseal cartilage complexes of newborn rats at a pressure of three bar and the cytokine content of the CIF was evaluated using an enzyme-linked immunosorbent assay (ELISA). SM exposed to CIF exhibited changes in the mRNA expression of cytokines, MMPs, TIMPs and components of the extracellular matrix. Incubating the SM with a cocktail of all factors found in CIF (CIF-like cocktail) demonstrated that this set of cytokines, to a considerable degree, imitates the effects of CIF.

\section{Materials and methods}

Animals. SMs were removed from the knee joints of specific pathogen-free, inbred, male Lewis rats $(n=24 ; 3$ months old $)$ purchased from the Animal Unit of the Mossakowski Medical Research Centre at the Polish Academy of Sciences (Warsaw, Poland). Three-to-five day-old inbred Lewis rats $(n=20)$ of both genders served as cartilage donors. The present study and the methods were approved by the Animal Ethics Committee of the Medical University of Warsaw (Warsaw, Poland).

Preparation of rat SMs. Rats were euthanized by inhalation of halothane. After opening the knee joint cavity, the SM was excised together with the patella, the patellar ligament and the joint capsule. The SM with the infrapatellar fat pad was then separated from the other tissues according to the method described previously (18).

Preparation of CIF. Newborn rats were euthanized by decapitation. CIF was rinsed out from the articular-epiphyseal cartilage complexes dissected from the newborn rats, with the exclusion of calcified fragments of the growth plate, which could be recognized and separated during dissection. After clearing from the surrounding tissues, cartilages from several animals were weighed. The mean weight of cartilage obtained from one animal was $110 \mathrm{mg}$. For CIF preparation, cartilage from 2 animals were placed in $2 \mathrm{ml}$ phosphate-buffered saline (PBS; Gibco-BRL, Paisley, UK) and cut into small fragments. Since cutting involves the exertion of pressure on the cartilage, some
CIF was probably already squeezed into PBS. The fluid together with the cartilage fragments was transferred into a $50 \mathrm{ml}$ Luer Lock syringe closed with the PTFE Body Two-Way Valve from Hamilton (Sigma-Aldrich Chemie, Steinheim, Germany) and the plunger was pressed to compress the air in the syringe so as to increase the pressure to three bar. Then, the plunger was slowly released. This procedure was repeated 20 times. Cutting the dissected cartilage and rinsing out the CIF lasted about 15-20 min. The fluid was separated from the cartilage fragments by centrifugation, and desalting was performed on PD-10 columns (Amersham Biosciences, Uppsala, Sweden) and lyophilized. CIF from 10-20 rats was pooled to obtain more uniform material. The lyophilisate was dissolved in RPMI-1640 (Gibco-BRL) medium and the protein content was determined. The total amount of protein in the CIF squeezed from the cartilage obtained from one animal varied from 0.87 to $1.1 \mathrm{mg}$. A working solution of CIF was standardized to contain $1 \mathrm{mg} / \mathrm{ml}$ protein. The presence and concentration of factors supposedly occurring in CIF [tumor necrosis factor (TNF), transforming growth factor $\beta 1$ (TGF $\beta 1)$, basic fibroblast growth factor (bFGF), platelet-derived growth factor (PDGF), epidermal growth factor (EGF), interleukin (IL)-1 $\beta$, IL-6, IL-7, IL-10, granulocyte-macrophage (GM)-colony-stimulating factor (CSF) granulocyte-macrophage (GM)-CSF, macrophage (M)-CSF, granulocyte (G)-CSF, insulin-like growth factor (IGF)-1, leukemia inhibitory factor (LIF), bone morphogenetic protein (BMP)2, BMP7, lubricin and hyaluronic acid (HA)] were estimated using an ELISA.

Chondrocyte culture. Cartilage fragments used for harvesting CIF were digested with constant stirring in an enzymatic solution containing $0.25 \%$ collagenase (type I), $0.05 \%$ DNase, $17.5 \mu \mathrm{M} \mathrm{N} \alpha$-p-tosyl-L-lysine chloromethyl ketone (TLCK) and $1 \%$ antibiotic-antimycotic solution (all from Sigma, St Louis, MO, USA) in RPMI-1640 medium (Gibco-BRL) for $3 \mathrm{~h}$ at $37^{\circ} \mathrm{C}$. The viability of chondrocytes was checked using the trypan blue test (Sigma). Chondrocytes were seeded into 24-well plates (Corning, Inc., Corning, NY, USA) at a density of 5x10 5 cells/well in $1 \mathrm{ml}$ of culture medium and observed for 7 days (10).

Incubation of SM. As a standard procedure, dissected SMs were incubated in RPMI-1640 (Gibco-BRL) medium in flat-bottomed 24-well plates (Corning, Inc.) in a humidified atmosphere of $5 \% \mathrm{CO}_{2}$ in air at $37^{\circ} \mathrm{C}$ with constant, slow motion, for $4 \mathrm{~h}$. The $\mathrm{SM}$ from one knee joint served as the control to the SM from the opposite knee. The control medium was enriched by $0.1 \%$ bovine albumin (Sigma). Experimental SMs were incubated either in CIF or in the CIF-like cocktail with commercial cytokines identical in concentration with that present in CIF. The following cytokines were used: G-CSF, M-CSF, LIF, BMP7 and bFGF (PromoKine; PromoCell GmbH, Heidelberg, Germany), TGF $\beta 1$ (Sigma) and IGF1 (R\&D Systems Inc., Minneapolis, MN, USA). After culture, total RNA from SM cells was isolated and the expression of genes encoding HAS1, HAS2, lubricin, collagen type I, aggrecan, versican, MMP2, MMP3, TIMP1, TIMP2, TIMP3, IL-1 $\beta$, IL-6, TNF and TGF $\beta 1$ was examined.

Protein determination. Ten microliters of CIF dissolved in the medium (without serum) or medium alone (blank test) was 
placed in a flat-bottomed 96-well plate (Corning, Inc.) and $0.2 \mathrm{ml}$ BCA protein assay reagent (Pierce, Rockford, IL, USA) was added to each well. The plate was incubated at $37^{\circ} \mathrm{C}$ for $30 \mathrm{~min}$. Protein concentrations were determined spectrophotometrically at $550 \mathrm{~nm}$ in a microplate reader (model 550; SLT Spectra Labinstruments, Crailsheim, Germany).

Analysis of CIF by ELISA. Cytokine and extracellular matrix protein levels were evaluated using rat immunoassay kits for IL-6, IL-10, TNF, TGF $\beta 1$, IGF1, GM-CSF and BMP2 from R\&D Systems, Inc., for IL-7, bFGF, M-CSF, G-CSF, LIF, BMP7, EGF and PDGF from Biotang, Inc. (Waltham, MA, USA), for HA and lubricin from Cusabio Biotech Co., Ltd. (Hubei, China), and for IL-1 $\beta$ from Life Technology (Frederick, MD, USA) according to the manufacturers' instructions.

Total RNA isolation from SM samples. RNA was isolated using a NucleoSpin ${ }^{\circledR}$ RNA II kit (Macherey-Nagel, Duren, Germany), according to manufacturer's instructions. The quantity and quality of the isolated total RNA was evaluated spectrophotometrically using a NanoDrop 2000 spectrophotometer (ND-2000) with software for the analysis of nucleic acids (both from Thermo Fisher Scientific, Wilmington, DE, USA).

Reverse transcription. Reverse transcription was performed using a High Capacity cDNA Reverse Transcription kit (Applied Biosystems, Warrington, UK) according to the manufacturer's instructions in an Eppendorf gradient Mastercycler (Eppendorf AG, Hamburg, Germany). cDNA samples were stored at $-20^{\circ} \mathrm{C}$.

Real-time polymerase chain reaction (PCR). Real-time PCR was performed in an ABI PRISM 7500 (Applied Biosystems) using 96-well optical plates. Each sample was run in triplicate and was supplied with an endogenous control [rat GAPDH endogenous control (VIC ${ }^{\circledR} / \mathrm{MGB}$ Probe)]. For gene expression analysis, the appropriate TaqMan expression assays was used. All probes were stained with FAM (Applied Biosystems). The reaction was run in $25 \mu \mathrm{l}$ mix of TaqMan Universal Master Mix, appropriate primer set, MGB probe and $50 \mathrm{ng}$ cDNA template. Universal thermal conditions $\left(10 \mathrm{~min}\right.$ at $95^{\circ} \mathrm{C}$, 40 cycles of $15 \mathrm{sec}$ at $95^{\circ} \mathrm{C}$ and $1 \mathrm{~min}$ at $60^{\circ} \mathrm{C}$ ) were used. Data analysis was performed using sequence detection software ver. 1.2 (Applied Biosystems). The amount of RNA transcript in SMs maintained in the control medium was estimated by $\Delta \mathrm{Ct}$.

Statistical analysis. Data were analyzed by the Wilcoxon matched-pair test or by the Mann-Whitney U test (Statistica software) (19). A p-value $<0.05$ was considered to indicate a statistically significant difference.

\section{Results}

More than $90 \%$ of chondrocytes isolated from cartilage fragments used for CIF production were viable and achieved 2 population doublings within 7 days of culture (data not shown), which were similar to the findings of a study examining chondrocytes isolated from intact cartilage (10).
Table I. Concentration of cytokines in CIF.

\begin{tabular}{lcc}
\hline Cytokine & $\begin{array}{c}\text { Mean concentration } \\
(\mathrm{pg} / \mathrm{ml}) \pm \mathrm{SD}\end{array}$ & $\begin{array}{c}\text { Cytokine concentration } \\
(\mathrm{pg} / 1 \mathrm{mg} \text { of cartilage })\end{array}$ \\
\hline bFGF & $2320 \pm 210$ & 21.1 \\
IGF1 & $2054 \pm 246$ & 18.7 \\
TGF $\beta 1$ & $517 \pm 96$ & 4.7 \\
BMP7 & $80.5 \pm 29$ & 0.73 \\
M-CSF & $61 \pm 15$ & 0.55 \\
LIF & $24 \pm 3$ & 0.22 \\
G-CSF & $23 \pm 5$ & 0.21 \\
\hline
\end{tabular}

CIF, cartilage interstitial fluid; bFGF, basic fibroblast growth factor; IGF1, insulin-like growth factor-1; TGF $\beta 1$, transforming growth factor $\beta 1$; BMP7, bone morphogenetic protein 7 ; M-CSF, macrophagecolony-stimulating factor LIF, leukemia inhibitory factor; G-CSF, granulocyte-colony-stimulating factor.

Seven cytokines were detected in the CIF following ELISA analysis (Table I). bFGF, and IGF1 predominated with the value $>2,000 \mathrm{pg} / \mathrm{ml}$, TGF $\beta 1$ reached $500 \mathrm{pg} / \mathrm{ml}$ whereas BMP7, M-CSF, G-CSF and LIF were $<100 \mathrm{pg} / \mathrm{ml}$. Nine cytokines (IL-1 $\beta$, IL-7, IL-6, IL-10, PDGF, EGF, TNF, GM-CSF and BMP2) were either absent or below the sensitivity level of the assay. The matrix proteins lubricin and HA were not detected. Cytokine concentrations present in the CIF and calculated per mg of wet weight of cartilage from which CIF was obtained are listed in Table I.

CIF stimulated the mRNA expression of HAS1 $(\mathrm{p}<0.005)$, HAS2 $(\mathrm{p}<0.005)$, lubricin $(\mathrm{p}<0.003)$, collagen type $\mathrm{I}(\mathrm{p}<0.005)$, versican $(\mathrm{p}<0.007)$, aggrecan $(\mathrm{p}<0.005)$, MMP2 $(\mathrm{p}<0.003)$, MMP3 (p<0.008), TIMP1 $(\mathrm{p}<0.008)$, TIMP2 $(\mathrm{p}<0.008)$, TIMP3 $(\mathrm{p}<0.008)$, IL-6 $(\mathrm{p}<0.03)$ and TGF $31(\mathrm{p}<0.005)$, whereas the expression of TNF $(p<0.002)$ and IL-1 $\beta(p<0.03)$ was inhibited (Fig. 1). Observations regarding the influence of factors present in CIF (CIF-like cocktail) on the SM were limited to nine selected genes (Fig. 2). CIF-like cocktail stimulated the mRNA expression of HAS1 $(p<0.01)$, lubricin $(\mathrm{p}<0.01)$, collagen type I $(\mathrm{p}<0.02)$, aggrecan $(\mathrm{p}<0.02)$, TIMP1 $(\mathrm{p}<0.02)$ and TGF $\beta 1(\mathrm{p}<0.01)$ genes. There was no statistical difference between the expression levels of these genes after CIF and CIF-like cocktail treatment (for HAS1 p $>0.05$, for the rest of genes $\mathrm{p}>0.1$ ). Contrary to CIF, CIF-like cocktail did not change the expression of MMP-3 ( $>>0.5)$, IL-6 ( $>0.25)$ and TNF ( $>>0.35)$ and therefore the mRNA levels of these genes were different from the mRNA levels following CIF treatment (for MMP3 and IL-6 p<0.01, for TNF $\mathrm{p}<0.05$ ).

\section{Discussion}

While presenting the first study detecting cytokines in CIF and its effects on the SM, to the best of our knowledge, we have to consider several limitations of this approach. The amount of available cartilage in newborn rats is low, and it is necessary to collect articular cartilage from many joints together with non-calcified fragments of growth plates which cannot be separated during dissection. It is, however, important that 


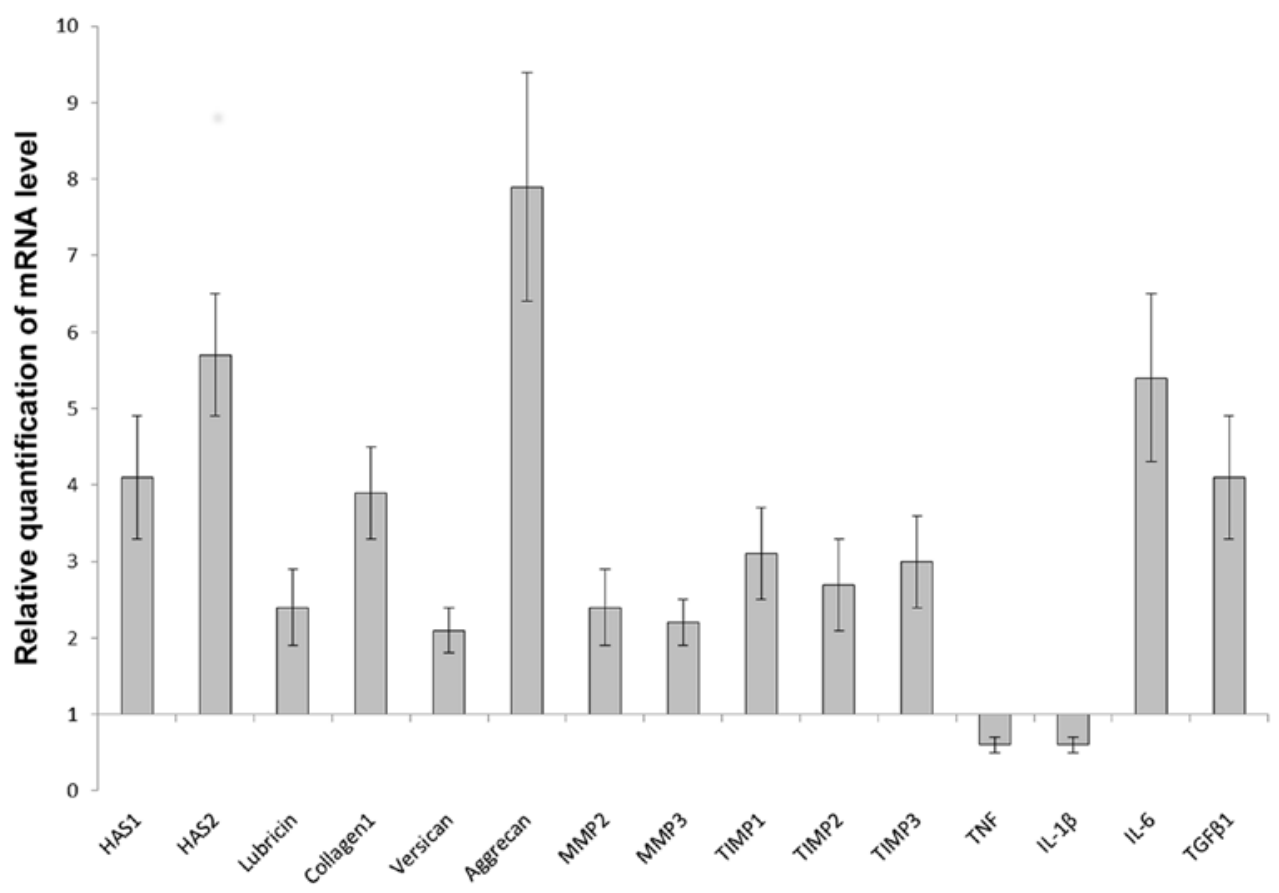

Figure 1. mRNA expression of hyaluronan synthase (HAS)1 and HAS2, extracellular matrix proteins, matrix metalloproteinases (MMPs), tissue inhibitors of metalloproteinase (TIMPs) and cytokines in the synovial membrane after $4 \mathrm{~h}$ of incubation with $1 \mathrm{mg} / \mathrm{ml}$ cartilage interstitial fluid (CIF) measured by real-time PCR. Values are expressed as the means \pm SE. In each group, $n=12$. Relative expression was calculated against the reference gene, GAPDH. Analysis was conducted as a relative quantification study, using control synovial membrane gene expression as a calibrator (value, 1). Differences in the expression of all genes were significant, according to the Wilcoxon matched-pair test at $\mathrm{p}<0.05$. TNF, tumor necrosis factor; IL-1 $\beta$, interleukin-1 $\beta$; IL-6, interleukin-6; TGF $\beta 1$, transforming growth factor $\beta 1$.

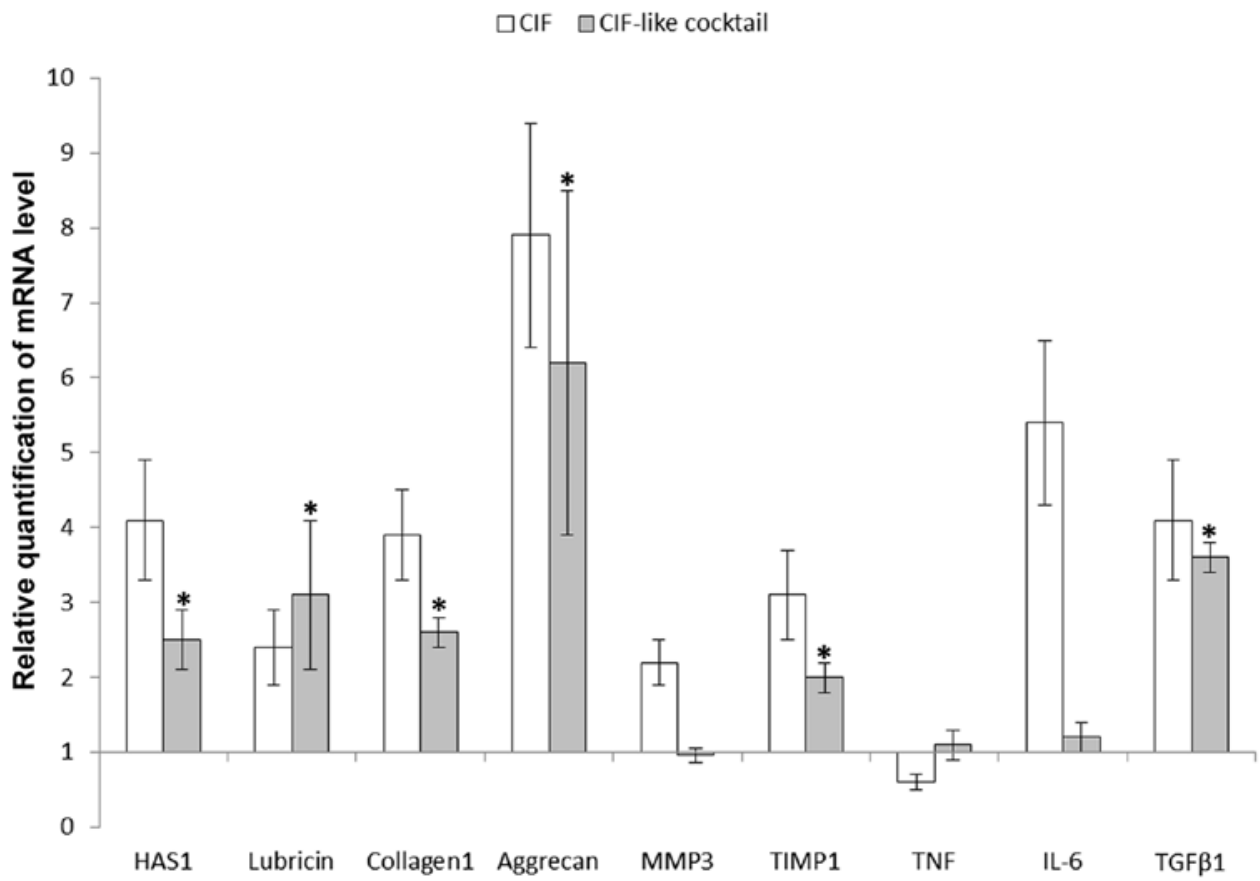

Figure 2. mRNA expression of hyaluronan synthase 1 (HAS1), matrix proteins, matrix metalloproteinase 3 (MMP3), tissue inhibitor of metalloproteinase 1 (TIMP1) and cytokines in the synovial membrane after $4 \mathrm{~h}$ of incubation with cartilage interstitial fluid (CIF) or CIF-like cocktail, measured by real-time PCR. Values are expressed as the means \pm SE. In each group, $n=12$. Relative expression was calculated against the reference gene, GAPDH. Lack of differences between the influence of CIF and CIF-like cocktail are marked with asterisks (Mann-Whitney U test). TNF, tumor necrosis factor; Il-6, interleukin-6; TGF $\beta 1$, transforming growth factor $\beta 1$.

CIF is prepared without damage to the chondrocytes, which after CIF harvesting, survived enzymatic isolation and grew in culture (data not shown). The concentrations of various factors in CIF probably represent their average value in the whole cartilage, without taking into consideration zonal chondrocyte distribution (20) and gradients between chondrocytes and 
territorial or interterritorial matrix. Cytokines are probably released, as we expected, following McCutchen's (13) theory of 'weeping' lubrication, during each loading of cartilage. Thus, their concentrations in the synovial fluid may vary depending on physical activity. Agents present in CIF (Table I) may act on chondrocytes in an auto- or paracrine fashion, or after being squeezed from the cartilage, during loading of the synovial cells. They may influence both the formation of cartilage matrix components and the production of cytokines.

The SM is formed from four main types of cells, namely synoviocytes (fibroblast-like cells), macrophages, adipocytes and epitheliocytes. Each of these cell types produces a panel of cytokines (17); thus, CIF may stimulate their secretion and they, in turn, may affect expression of particular genes.

Numerous studies describe the effects of particular factors detected in CIF on the expression of connective tissue matrix components. Thus, IGF1 stimulates the synthesis of cartilage matrix proteins $(21,22)$ and collagen type I $(23)$. IGFs are also presumably the major regulatory factors of cartilage proteoglycan synthesis present in human synovial fluid (24). TGF $\beta 1$ is involved in the control of differentiation and dedifferentiation of chondrocytes, the synthesis of collagen type II and proteoglycans, and maintaining the homeostasis of cartilage (25). It also enhances the mRNA expression of type I collagen (26).

CIF and CIF-like cocktail stimulated the mRNA expression of collagen type I and aggrecan, a proteoglycan specific for cartilage (Fig. 2) in the SM. The presence in CIF of both IGF1 and TGF $\beta 1$ may be important for keeping chondrocytes in the differentiated state, since these factors, acting jointly, reexpressed aggrecan and type II collagen genes in dedifferentiated articular chondrocytes (27). A similar synergistic action of both factors was observed by Seifarth et al (28), who found that chondrocytes dedifferentiated by IL-1 regained a chondrocyte-like phenotype after treatment with IGF1 and/or TGF $\beta 1$ alone, but co-treatment with IGF1 and TGF $\beta 1$ exerted additive anabolic effects.

TGF $\beta 1$ stimulated HAS1 expression in fibroblasts (29) and hyaluronan synthesis in rat SM (16). The expression of lubricin and HAS1 was also stimulated by CIF and CIF-like cocktail (Fig. 2) suggesting that the factors present in CIF may influence joint lubrication.

TGF $\beta 1$ inhibited MMP3 synthesis and stimulated TIMP1 production in various tissues (30). CIF, however, increased the mRNA expression of MMP3 and TIMP1 whereas CIF-like cocktail had no effect on MMP3 but stimulated the expression of TIMP1.

Since TGF $\beta 1$ can induce its own gene expression (31), CIF and CIF-like cocktail could stimulate TGF $\beta 1$ expression through a similar mechanism (Fig. 2).

bFGF is synthesized by chondrocytes and functions as an autocrine/paracrine mitogen via its deposition into the cartilage extracellular matrix and subsequent release depending on the biological activity of cartilage (32). It may, depending on the dose and age of cartilage, stimulate or inhibit the synthesis of matrix proteins and accelerate proteoglycan degradation $(21,33)$. bFGF was present in CIF at a relatively high concentration but in view of the above-mentioned reports, its effect on the SM is difficult to estimate.

The low content in CIF of G-CSF and M-CSF is in agreement with observations that they were absent or present at low levels in unstimulated cultures of articular cartilage or chondrocytes $(34,35)$.

LIF, a member of the IL-6 family of cytokines, displays pleiotropic effects on various cell types and organs (36). It was not detected in non-stimulated, short-term chondrocyte cultures, but appeared after stimulation with IL-1 or TNF (37). The small amount of LIF detected in CIF is in agreement with these observations (Table I).

Comparing the effects of CIF with those evoked by a CIF-like cocktail indicates that in the latter some factors were missing. Particularly, CIF-like cocktail did not contain factors responsible for the stimulation of IL- 6 gene expression and inhibition of TNF gene expression (Fig. 2).

IL-6 is a multifunctional cytokine with well-defined pro- and anti-inflammatory properties (38). It is produced by articular chondrocytes (39), and by the four main cell types in the SM (17). TGF $\beta 1$ increased IL- 6 production by chondrocytes (39) and human fibroblasts (40) but IGF1 had no significant effect (39). In the present study, CIF strongly increased the mRNA expression of IL-6, but CIF-like cocktail had no effect.

TNF is a major proinflammatory mediator with a marked functional duality, being strongly engaged both in tissue regeneration/expansion and destruction (41). TNF is expressed in macrophages (42) which are presumably its main source in the SM (17). The administration of CIF inhibited TNF expression, whereas CIF-like cocktail had no statistically valid effect (Fig. 2). The reason for differences in the expression of TNF in the SM under the influence of CIF and CIF-like cocktail remains unclear, since exposing macrophages to IGF1 at a dose similar to that present in CIF and CIF-like cocktail enhanced TNF release and its mRNA level (43).

To sum up, the stimulatory effect of CIF on collagen type I and aggrecan expression observed in this study is in accord with previously published data demonstrating increased expression under the influence of IGF1 and TGF $\beta 1$. It is also interesting that in the case of MMP3, TIMP1 and IL-6, CIF exerted stimulatory effects whereas CIF-like cocktail stimulated only the expression of TIMP1. On the other hand, CIF inhibited TNF expression and CIF-like cocktail had no effect. It suggests a need for further, more thorough studies on the content of CIF, and also indicates that the influence of CIF on the SM may not only depend on the activity of particular factors but also on their interactions.

Harvesting CIF from the cartilage of larger animals and humans in order to determine its contents may require more sophisticated equipment than a syringe. Once, however, technical problems have been resolved, studies on CIF may provide valuable information regarding the relationship between cartilage and the SM in physiological and pathological states.

\section{Acknowledgements}

The study was supported by the National ScienceCentre(Poland) on the basis of decision number: DEC-2012/05/B/NZ4/02646.

\section{References}

1. Swann DA: Structure and function of lubricin, the glycoprotein responsible for the boundary lubrication of articular cartilage. In: Articular Synovium. Franchimont P and Karger S (eds). Basel, pp45-58, 1982. 
2. Hui AY, McCarty WJ, Masuda K, Firestein GS and Sah RL: A systems biology approach to synovial joint lubrication in health, injury, and disease. Wiley Interdiscip Rev Syst Biol Med 4: 15-37, 2012.

3. Bandara G, Georgescu HI, Lin CW and Evans CH: Synovial activation of chondrocytes: evidence for complex cytokine interactions. Agents Actions 34: 285-288, 1991.

4. Lee DA, Salih V, Stockton EF, Stanton JS and Bentley G: Effect of normal synovial fluid on the metabolism of articular chondrocytes in vitro. Clin Orthop Relat Res 342: 228-238, 1997.

5. Hirsch MS, Lunsford LE, Trinkaus-Randall V and Svoboda KK: Chondrocyte survival and differentiation in situ are integrin mediated. Dev Dyn 210: 249-263, 1997.

6. Jakob M, Démarteau O, Schäfer D, Stumm M, Heberer M and Martin I: Enzymatic digestion of adult human articular cartilage yields a small fraction of the total available cells. Connect Tissue Res 44: 173-180, 2003.

7. Hayman DM, Blumberg TJ, Scott CC and Athanasiou KA: The effects of isolation on chondrocyte gene expression. Tissue Eng 12: 2573-2581, 2006

8. Schulze-Tanzil G, de Souza P, Villegas Castrejon H, John T, Merker HJ, Scheid A and Shakibaei M: Redifferentiation of dedifferentiated human chondrocytes in high-density cultures. Cell Tissue Res 308: 371-379, 2002

9. Marlovits S, Hombauer M, Tamandl D, Vècsei V and Schlegel W: Quantitative analysis of gene expression in human articular chondrocytes in monolayer culture. Int J Mol Med 13: 281-287, 2004.

10. Osiecka-Iwan A, Hyc A, Niderla-Bielińska J and Moskalewski S: Chondrocyte-associated antigen and matrix components in a 2-and 3-dimensional culture of rat chondrocytes. Mol Med Rep 1: 881-887, 2008

11. Polacek M, Bruun J-A, Elvenes J, Figenschau Y and Martinez I The secretory profiles of cultured human articular chondrocytes and mesenchymal stem cells: implications for autologous cell transplantation strategies. Cell Transplant 20: 1381-1393, 2011.

12. Melas IN, Chairakaki AD, Chatzopoulou EI, Messinis DE, Katopodi T, Pliaka V, Samara S, Mitsos A, Dailiana Z, Kollia P and Alexopoulos LG: Modeling of signaling pathways in chondrocytes based on phosphoproteomic and cytokine release data. Osteoarthritis Cartilage 22: 509-518, 2014.

13. McCutchen CW: Sponge-hydrostatic and weeping bearings. Nature 184: 1284-1285, 1959.

14. Morrell KC, Hodge WA, Krebs DE and Mann RW: Corroboration of in vivo cartilage pressures with implications for synovial joint tribology and osteoarthritis causation. Proc Natl Acad Sci USA 102: 14819-14824, 2005.

15. Caligaris M and Ateshian GA: Effects of sustained interstitial fluid pressurization under migrating contact area, and boundary lubrication by synovial fluid, on cartilage friction. Osteoarthritis Cartilage 16: 1220-1227, 2008

16. Hyc A, Osiecka-Iwan A, Niderla-Bielińska J, Jankowska-Steifer E and Moskalewski S: Pro- and anti-inflammatory cytokines increase hyaluronan production by rat synovial membrane in vitro. Int J Mol Med 24: 579-585, 2009.

17. Hyc A, Osiecka-Iwan A, Niderla-Bielińska J and Moskalewski S Influence of LPS, TNF, TGF- $\beta 1$ and IL-4 on the expression of MMPs, TIMPs and selected cytokines in rat synovial membranes incubated in vitro. Int J Mol Med 27: 127-137, 2011.

18. Hyc A, Osiecka-Iwan A, Dziunycz P and Moskalewski S: Preparation of rat synovial membrane for studies of cytokine secretion. Folia Histochem Cytobiol 45: 57-60, 2007.

19. Livak KJ and Schmittgen TD: Analysis of relative gene expression data using real-time quantitative PCR and the 2(-Delta Delta C(T)) Method. Methods 25: 402-408, 2001.

20. Darling EM and Athanasiou KA: Growth factor impact on articular cartilage subpopulations. Cell Tissue Res 322: 463-473, 2005.

21. Sah RL, Chen AC, Grodzinsky AJ and Trippel SB: Differential effects of bFGF and IGF-I on matrix metabolism in calf and adult bovine cartilage explants. Arch Biochem Biophys 308: 137-147, 1994.

22. Trippel SB: Growth factor actions on articular cartilage. J Rheumatol Suppl 43: 129-132, 1995.

23. Blackstock CD, Higashi Y, Sukhanov S, Shai SY, Stefanovic B, Tabony AM, Yoshida T and Delafontaine P: Insulin-like growth factor-1 increases synthesis of collagen type I via induction of the mRNA-binding protein LARP6 expression and binding to the 5 ' stem-loop of COL1a1 and COL1a2 mRNA. J Biol Chem 289 7264-7274, 2014
24. Schalkwijk J, Joosten LA, van den Berg WB, van Wyk JJ and van de Putte LB: Insulin-like growth factor stimulation of chondrocyte proteoglycan synthesis by human synovial fluid. Arthritis Rheum 32: 66-71, 1989.

25. Patil AS, Sable RB and Kothari RM: An update on transforming growth factor- $\beta$ (TGF- $\beta$ ): sources, types, functions and clinical applicability for cartilage/bone healing. J Cell Physiol 226: 3094-3103, 2011

26. Verrecchia F and Mauviel A: TGF- $\beta$ and TNF- $\alpha$ : Antagonistic cytokines controlling type I collagen gene expression. Cell Signal 16: 873-880, 2004.

27. Yaeger PC, Masi TL, de Ortiz JL, Binette F, Tubo R and McPherson JM: Synergistic action of transforming growth factor- $\beta$ and insulin-like growth factor-I induces expression of type II collagen and aggrecan genes in adult human articular chondrocytes. Exp Cell Res 237: 318-325, 1997.

28. Seifarth C, Csaki C and Shakibaei M: Anabolic actions of IGF-I and TGF- $\beta 1$ on interleukin-1 $\beta$-treated human articular chondrocytes: Evaluation in two and three dimensional cultures. Histol Histopathol 24: 1245-1262, 2009.

29. Campo GM, Avenoso A, Campo S, D'Ascola A, Traina P and Calatroni A: Effects of cytokines on hyaluronan synthase activity and response to oxidative stress by fibroblasts. Br J Biomed Sci 66: 28-36, 2009

30. Barrientos S, Stojadinovic O, Golinko MS, Brem H and Tomic-Canic M: Growth factors and cytokines in wound healing. Wound Repair Regen 16: 585-601, 2008.

31. Piek E, Ju WJ, Heyer J, Escalante-Alcalde D, Stewart CL, Weinstein M, Deng C, Kucherlapati R, Bottinger EP and Roberts AB: Functional characterization of transforming growth factor beta signaling in Smad2- and Smad3-deficient fibroblasts. J Biol Chem 276: 19945-19953, 2001.

32. Luan Y, Praul CA, Gay CV and Leach RM Jr: Basic fibroblast growth factor: an autocrine growth factor for epiphyseal growth plate chondrocytes. J Cell Biochem 62: 372-382, 1996.

33. Loeser RF, Chubinskaya S, Pacione $\mathrm{C}$ and $\mathrm{Im} \mathrm{HJ}$ : Basic fibroblast growth factor inhibits the anabolic activity of insulin-like growth factor 1 and osteogenic protein 1 in adult human articular chondrocytes. Arthritis Rheum 52: 3910-3917, 2005

34. Alsalameh S, Firestein GS, Oez S, Kurrle R, Kalden JR and Burmester GR: Regulation of granulocyte macrophage colony stimulating factor production by human articular chondrocytes. Induction by both tumor necrosis factor-alpha and interleukin 1 , downregulation by transforming growth factor $\beta$ and upregulation by fibroblast growth factor. J Rheumatol 21: 993-1002, 1994.

35. Campbell IK, Ianches G and Hamilton JA: Production of macrophage colony-stimulating factor (M-CSF) by human articular cartilage and chondrocytes. Modulation by interleukin-1 and tumor necrosis factor alpha. Biochim Biophys Acta 1182: 57-63, 1993.

36. Mathieu ME, Saucourt C, Mournetas V, Gauthereau X, Thézé N, Praloran V, Thiébaud $\mathrm{P}$ and Bœuf H: LIF-dependent signaling: new pieces in the Lego. Stem Cell Rev 8: 1-15, 2012.

37. Henrotin YE, De Groote DD, Labasse AH, Gaspar SE, Zheng SX, Geenen VG and Reginster JY: Effects of exogenous IL-1 $\beta$, TNF alpha, IL-6, IL-8 and LIF on cytokine production by human articular chondrocytes. Osteoarthritis Cartilage 4: 163-173, 1996.

38. Wolf J, Rose-John S and Garbers C: Interleukin- 6 and its receptors: a highly regulated and dynamic system. Cytokine 70: $11-20,2014$

39. Guerne PA, Carson DA and Lotz M: IL-6 production by human articular chondrocytes. Modulation of its synthesis by cytokines, growth factors, and hormones in vitro. J Immunol 144: 499-505, 1990.

40. Seong GJ, Hong S, Jung SA, Lee JJ, Lim E, Kim SJ and Lee JH: TGF- $\beta$-induced interleukin- 6 participates in transdifferentiation of human Tenon's fibroblasts to myofibroblasts. Mol Vis 15: 2123-2128, 2009

41. Wajant H, Pfizenmaier K and Scheurich P: Tumor necrosis factor signaling. Cell Death Differ 10: 45-65, 2003.

42. Nathan CF: Secretory products of macrophages. J Clin Invest 79: 319-326, 1987.

43. Renier G, Clément I, Desfaits AC and Lambert A: Direct stimulatory effect of insulin-like growth factor-I on monocyte and macrophage tumor necrosis factor-alpha production. Endocrinology 137: 4611-4618, 1996. 